\title{
The Change and Construction of Chinese National Image in 1949-2019
}

\author{
Zhu Hailong ${ }^{1}$ \\ ${ }^{1}$ Marxist School, Guangdong University of Foreign Studies, Guangzhou, China \\ Correspondence: Zhu Hailong, Marxist School, Guangdong University of Foreign Studies, Guangzhou, China.
}

Received: September 10, 2019 Accepted: October 18, 2019 Online Published: October 20, 2019

doi: 10.5539/elt.v12n11p35 URL: https://doi.org/10.5539/elt.v12n11p35

\begin{abstract}
The image of country is overall impression and evaluation of the country itself given by countries and people at home and abroad. It is a concrete expression of the country's strategic resources and overall strength. Since the founding of the People's Republic of China, its national image has evolved over the past 70 years. It has realized the transformation from a monist image of "political supremacy" to "democracy, livelihood, and civil rights", from a poor and backward country in the East to a rich and advanced socialist country, and from "hard power" to "soft power". In the future, the national image construction needs to improve the theoretical building and strengthen the top-level design, highlight the strategic perspective of the international communication system, expand the communication path, and enhance the time-effectiveness of the dissemination of the Chinese national image.
\end{abstract}

Keywords: China, national image, changes, construction

\section{Introduction}

Since the founding of the People's Republic of China 70 years ago, with a series of achievements in economic, political, cultural and social construction, China's national image has changed its inherent impression of poverty and backwardness in the past, has entered a new era of building a prosperous and developed socialist nation. As a strategic image of serving the country's internal affairs and diplomacy, the building of the country's image is more urgent than ever.

As president Xi Jinping pointed out, "We must pay attention to shaping the country's national image. It focuses on displaying the image of a great civilized country with profound history, diverse ethnic groups, and diverse and harmonious cultures. Political clarity, economic development, cultural prosperity, social stability, people's Unity, beautiful image of the East; We will uphold the image of a responsible major country that is peaceful, promotes common development, upholds international fairness and justice, and contributes to mankind. China is more open to the outside world, more affinity, full of hope and vitality of the image of a major socialist country (Xi, 2013). At the same time, facing the globalization, information-based, and diversified domestic and foreign environments, China has been soberly aware that it is not a day's work, but a long-term, dynamic, and systematic strategic project.

\section{A Conceptual Interpretation of the Image of Nation}

Scholars all around the world have different emphasis on the definition of national image, and have interpreted the specific connotation from a certain aspect. For example, Zhangkun believes that "the so-called national image is a comprehensive impression of a specific country in the eyes of the public all around the world, or a cognitive and subjective evaluation of the objective existence and realistic behavior of the domestic and foreign public in a specific country" (Zhang, 2018). From the perspective of factor analysis, Yuhong agrees that "national image is the overall understanding of the material elements, spiritual elements, institutional elements, and behavioral elements of a country by domestic and foreign audiences" (Yu, 2014). Liujinan defines the country from the perspective of extraterritorial countries. "The image of the country is the comprehensive assessment and overall impression from other countries" (Liu, 2019).

Matthew, a British scholar, recognizes that "the survival of positive national self-image helps maintain political order, public identity, and policy support" (Matthew, 1993). It is not difficult to see that no matter what perspective scholars distinguish and analyze the image of the country from, as the soft power and strategic image 
of the country's culture, the significance of its service and the internal affairs for diplomacy has been highlighted. It can be seen that the image of the nation has irreplaceable significance.

\section{The 70 Years Change of Chinese National Image: The Achievements Already Gotten}

Standing at the historical node of the 70 years of founding of the People's Republic of China and 40 years of reform and opening up, looking back on history, we can find that it is not only the change from historical situation of the country, the people's living standards, but also the national image. Overall, there are three historical advances:

\subsection{The Chinese National Image Has Been Successfully Transformed From the Monist Image of "Political Supremacy" to the Image of "Democracy, People'S Livelihood, and Civil Rights"}

At the beginning of the founding of the People's Republic of China, China's national economy was on the verge of collapse, and there were still the difficult tasks of reforming national capital, improving social system, and suppressing bandits in the Southwest. Externally, although the three years of the Korean War ended with the victory of China and North Korea, the U.S.-led UN military failed, but it also greatly consumed the precious national strength of the early days of the founding of the country. In this context, in order to bring together the people of the whole country, work together and resolve the external crisis of the country, only make full use of political weapons.

Therefore, using this strategy, China has completed the "five-year plan" of the national economy in the shortest time, and fought for a precious peace situation. At the same time, it also left behind a monist national image of "political supremacy." The ensuing "Great Leap Forward" and "People's Commune" have further solidified this impression. The ten-year catastrophe of the "Cultural Revolution" has brought China image of "political supremacy" to its peak and has affected for many years.

The convening of the Third Plenary Session of the Eleventh CPC Central Committee marked the opening of the historical curtain of reform and opening up in China, and the country's image was gradually reconstructed in the overall situation of "opening up". Chief designer Deng Xiaoping's speech on the southern tour not only strengthened China's confidence in taking the road of reform and opening up, but also made China's new national image different from the past. From the 14th to the 19th National Congress of the Party, through the unremitting efforts led by Jiang Zemin, Hujingtao, and Xi Jinping, China has developed the economy, served the people's livelihood, promoted democracy.

Built a powerful socialist country, and realize the dream of the great rejuvenation of the Chinese nation has been the concept of governing the country. China's international status, people's living standards, ecological civilization, and democratic political development have gotten outstanding achievements in a series of key areas. The national image of democracy, people's livelihood, and civil rights has been established.

\subsection{The Image of the Chinese Nation Has Turned From a Poor and Backward Eastern Country to a Rich and Advanced Socialist Country}

In the three decades since the founding of the People's Republic of China, due to the complex situation at home and abroad, the track and center of gravity of national construction have not been able to completely turn to the overall goal of economic construction and improvement of people's livelihood. The state has always been lagging behind in terms of economic development, scientific research, and international status. China's foreign exchange reserves, gross national product (GDP), citizens 'food and clothing, and education are all at the bottom of the world rankings. And computer, nuclear energy, information technology, high-speed rail technology, aircraft manufacturing, shipbuilding and other areas that are closely related to international people's livelihood are lagging behind. It is completely incompatible with China's status as a major country. The image of the China has been defined as an ancient Eastern country that is both backward and poor and self-isolated.

Forty years after the reform and opening up, with the rapid development of the country's overall strength, China gradually removed the hat of poverty and backwardness. Up to now, China is the second largest economy in the world, with foreign exchange reserves exceeding the $\$ 3$ trillion mark. It is not only an important member of the WTO, the World Bank and the G20, but also bears more major country responsibilities in global governance and international politics. For example, China will firmly support the multilateral system for international trade, establish and operate the Asian Investment Development Bank, launch the Belt and Road Strategy, the Silk Road Fund Plan, the Central African Cooperation Forum, and the Latin American Free Trade Area Construction Plan. The Chinese government is maximizing the benefits of development for cooperating countries and building a community of shared future for mankind. At the same time, China's scientific and technological progress has also allowed the world to share the joy of success. The "four major inventions" of the new era, high-speed rail, 
shared bicycles, electronic payments, and the Internet of Things are all promoting the construction of a global village. China's $5 \mathrm{G}$ communications technology, Beidou navigation satellites, large aircraft, nuclear power, and shipbuilding are developing sharply. The image of an advanced socialist power is taking root.

\subsection{The Construction of Chinese National Image From "Hard Power" to "Soft Power"}

The 70 years has taught China that to raise the country's overall national strength, raise the people's living standards, and move towards the center of the international community to realize the great rejuvenation of the Chinese nation, enough economic strength, developed science and technology, or advanced production technology are needed emergently. The "hard power", such as modern military forces, will never be able to do so. Therefore, China has worked hard on these "hard cores" and made full efforts. Of course, it has also achieved brilliant achievements. It took only a few decades to complete the 200 years of history of developed countries. China's "hard power" such as China's road, China Bridge, China's speed, and China's technology have left a deep impression on the world.

At the same time, China should also see that nation-building requires not only "hard power" but also "soft power". The report of the 19th National Congress of the CPC pointed out that "we must promote international communication capacity-building, tell good Chinese stories, show a true, three-dimensional, and comprehensive China, and improve the country's cultural strength. "It is in this context that China's National soft power construction has entered the" fast lane. "For example, the establishment of the State Administration of Radio and Television, the production of Chinese national propaganda films abroad, and the increase of overseas publicity have all achieved great success in propaganda films such as "China on the tip of the tongue", "China on the air" and "China One Minute".

The Central CCTV Overseas International Station has settled in many countries. Hiring local staff to participate in operations and multilingual broadcasts has greatly deepened the local people's understanding of distant China. In line with the Belt and Road Plan, the Chinese Ministry of Education has launched a training program for international students from countries along the Belt and Road, which has attracted a large number of outstanding students from countries along the route to study in China and promote cultural and people-to-people exchanges. It reduces the possible rejection from the other party. "Soft power" has become a beautiful new business card in the Chinese national image.

\section{The Future Construction of Chinese National Image: Strategy and Path}

Despite the proud achievements have been gotten, China still needs serious reflection from the perspective of strategy and implementation, in the face of changing times, complex international situations and high expectations from the people.

\subsection{To Define a Strategy for Building the Image of the Country}

The construction of national image is not a day's work, but a strategic project that needs long-term endeavor.

\section{1) Perfect the Construction of the State Image Theory}

The systematic theory provides comprehensive spiritual support and direction for practice, and is an indispensable intellectual factor for the successful development of construction practice. The building of national image should be stayed at the study of general countermeasure, but needs to enhance its scientific, logical, overall and academic rationality. On the other hand, guided by Xi Jinping's socialism thought with Chinese characteristics in the new era, he accurately grasped the essence of the country's image and made in-depth comparisons with China's national image at different times.

China will deepen the research on the forming mechanism, mode of action, transmission path, function orientation and basic framework of the current national image. At the same time, encourage mu ltidisciplinary cross-integration, use multidisciplinary forces to invest in the study of the country's image, enrich, expand, and improve the systematic theoretical construction. In the new era of information and globalization, a single discipline cannot support the study of the country's image. Only by exerting the advantages of different disciplines, integrating them, and coordinating which can we support and expand the results of research from different perspectives.

\section{2) Strengthen Top Level Design and Build International Communication System}

The shaping, positioning and dissemination of the country's image is an important part of the country's "soft power". It cannot be accomplished with high quality by relying solely on local governments, non-governmental organizations and citizens. The important premise is that the central government must first improve the top-level design and clearly define the direction of development. To build an effective communication system can be 
targeted and strive for the upper reaches. Looking at overseas, all major countries that are important in the international community have spared no effort to strengthen the top-level design of their national image and expand new channels for international communication.

Such as the United States, the U.K., etc, relying on all their own VOA, FOX, BBC radio stations, Washington Daily Mail, The Times, and online information platforms to convey their own values and national images to the world. Because these countries attach great importance to the dominance of public opinion, they have long invested heavily in global news field, mergers and expansion, through branch media organizations all over the world, and even monopolize the dominance of international news opinion. It has constructed a pattern of news and public opinion from the paper media, online media to the media, which has become a powerful tool for consolidating their national image.

The emerging Russia has made outstanding achievements in the international dissemination of its national image. It has established "Russia Today" television stations in a number of developed west countries to spread Russian values and has attracted great attention in international society. It was once considered by the Western powers as the most difficult news force to deal with and was shut down. Based on Russian successful experience, China can continue to expand overseas broadcasting on the basis of the existing CCTV4 overseas channels, so that more countries, especially those along the Belt and Road, and those with major interests, can understand China's current development and progress. Through the international dissemination of national image, China will build up domestic consensus and expand the international "circle of friends".

\subsection{A New Way for Chinese Government to Expand the National Image Building}

1) Full use of WeChat, social platforms, networks, self-media, AI to expand the internal and external dissemination of the country's image

National image communication needs technical media and diversified communication channels. Since the beginning of the 21 st century, China has made outstanding achievements in communication technology. China is already at the forefront of the world in the areas of the Internet, the Internet of Things, $5 \mathrm{G}$ communications, AI, and big data research and development. This provides China with a good period of opportunity and available way to create and disseminate a national image. Technology, while not of value in itself, can be used to disseminate national intentions and shape national images. Technology companies such as Microsoft, Qualcomm, Dell, GPS, Boeing and Airbus have successfully shaped and spread the image of technology powers in the United States and Europe in the process of leading technological change.

Multimedia and self-media are important land for national image construction and dissemination, needed to be operated for a long time. As we all know, in the era of network information, the dissemination of the national image mainly depends on multimedia such as television, radio, paper media, Internet, and mobile phone platforms. Through the method, the audience receives the main national information and constructs an impression of the country, especially for overseas people. Therefore, on the basis of consolidating the advantages of traditional media, China can use the existing communication and network technologies to produce and embed national image information and publicize China's development achievements in different fields. For example, "China One Minute", "China on the tip of the tongue" and "Bell" allow more people at home and abroad to understand the other side of China's social development, Conveying the image of a country with a sense of affinity to the rest of the world.

\section{2) Using Stars and Idol to Spread Chinese Image}

Stars and idols are not only natural persons, but also special public figures representing the image of the country. They can play a positive role in promoting the image of China. Idol characters such as performing arts stars, singers, and sports stars are easy to attract people and become silent weapons for receiving "fans". Their role has been valued by many countries. The United States has successfully used heroes in Hollywood films, such as Captain America, Iron Man, and Batman, to create the just image of American heroes. The patriotic film "Top Gun" once shot by Tom Cruize has inspired a large number of young people to join U.S. army. The number of volunteers in the U.S. increased by $2 \%$ that year. The British used 007, Mr. Bean, Piglet Page, Teddy bear, to create the classic image of Britain. India uses "Bollywood" to create an open image of contemporary India. South Korea uses a large number of performing arts and singing stars to create the image of South Korea's cultural power, such as "Uncle Bird" of "Jiangnan Style" and star Ryan. They even stepped into the United Nations to speak for their own culture. Set off a "Korean flow", with public figures as the carrier of the dissemination of ways worth China learning.

At present, Chinese overseas who have a high degree of recognition include Bruce Lee, Jackie Chan, Zhang Ziyi, 
Gong Li, Yao Ming, Li Na, and TBOYS. Among them, young stars such as Guanxiaotong and others stepped into the United Nations to speak. It has established a good image of Chinese youth in the new era. A song "little Apple" is also popular around the world, allowing the world to blow an "Apple wind." Despite this, Chinese stars in the international society have less influence than in Europe and the United States, and even South Korea keep digging up more successful figures and create Chinese classics in different fields so that they can display China's image on the international stage, the United Nations, the Cannes Film Festival and fashion shows, would be used to enhance the international reputation of China's open and confident image.

3) Dissemination of China's national image through the Belt and Road Initiative, the Central African Cooperation Forum and the AIIB

As a responsible international power, China should become a framer of international rules and a defender of the new international order. At present, it is estimated that rulemaking in economic, political, military, and technical fields is in the hands of Western alliance led by the United States. After 40 years of reform and opening up, China has achieved remarkable results in many fields. The law of developing power to change the image of the country has come to a critical stage. For this reason, countries with vested interests in international rule-making will not be happy to see China become a rule-maker.

At this time, China is sticking to its own strategic determination, focus on the development of a "community of common destiny for mankind", win more circles of friends through peaceful rise, and gain more international understanding and trust. The Belt and Road Initiative, the Central African Cooperation Forum, the China-Arab Forum, the Shanghai Cooperation Organization and the AIIB are key strategies for building a community of shared future for mankind. Mutual understanding and trust is the key to maintain a community of shared future for mankind. Understanding China is a prerequisite, and our country's national image is a magic method to infect and attract countries along the route.

By clarifying cooperation intentions, building infrastructure, investing in foreign capital, medical assistance, disaster relief, educational cooperation, cultural exchanges and technological research and development, China can spread its image of prosperity, peace and responsibility to countries along the routes. Let cooperation and development and the sharing of results be the best forms of spreading the image of the Chinese nation.

4) Play the National Image Construction by Confucius Institute

Confucius Institute is one of the excellent platforms for spreading Chinese traditional culture and making friends all around the world. Since the establishment of the first Confucius Institute in Seoul, South Korea, in November 2004, there have been more than a thousand Confucius Institutes across four continents that have played an active cultural communication and heart-to-heart exchange role. With the overall improvement of China's influence, China has entered the center of the international stage, and its appeal has grown. International society wants to know more about China. This is also a good opportunity for us to spread our national image.

With the deepening of international cooperation, Chinese technology, standards, and talents are rapidly going out, and they need to be integrated with the local needs and help the local residents. In this process, language is a tool for communication, culture is the basis of understanding, and psychology is a fertile land for cooperative identification. This can be gradually realized through long-term language teaching and cultural exchanges. We should take the need as the guide, adjust the global layout of the Confucius Institute, and strive to give priority to the countries along the Belt and Road, Africa, South America, and emerging economies.

Focus on the distribution of core interests of countries, key universities, and middle schools, so that the dissemination of Chinese culture extends to all interested countries, affecting key groups and key figures, making efforts to sink cultural influence into school-age children. By expanding scholarships for international students from countries along the Belt and Road, we will attract more college students and middle school students to study and live in China, so that they will be willing to come and stay, so as to cultivate the friendly generation and expand their influence in the country through them.

5) Deepen the Connotation of "Lady's Diplomacy" and Promote the Construction of China's National Image

"Lady diplomacy" is popular in the international diplomatic etiquette, and it is of great significance in shaping a country's image of affinity and building a bridge between people's hearts and minds. Because of their unique gentle temperament and soft posture, women can often get more recognition when carrying out diplomatic and foreign activities. In the Western diplomatic arena, the "first lady" often plays a very important role. Whether it is from temperament, speech or image creation, it can show a country's cultural soft power and play an irreplaceable role in displaying the country's image.

The United States is an active country in wife's diplomacy and has always had a cultural tradition of expanding 
her diplomatic influence. After the 21st century, it is more frequent. From Bush, George W. Bush, Clinton, Obama to President Donald Trump, the "First Lady" set off a new wave of diplomacy. Trump in particular, not only wife diplomacy, but also daughter diplomacy, granddaughter diplomacy, has a profound impact. When Mr. President Xi Jinping visited the US, for example, a Chinese song by Mr. Trump's granddaughter refreshed the world.

Europe is an important stage for his wife's diplomacy. Former French President Nicolas Sarkozy, Hollande, and current President often carry out foreign affairs activities with his wife. Although the German and British Prime Ministers are women, they also carry out visits with their husbands and extend their diplomacy to "Mr. Diplomacy." Other European countries have spared no effort to carry out their wife's diplomacy and actively create a national image of their own people.

There is no doubt that the good image of the First Lady is conducive to enhancing the self-confidence of the people, and it is conducive to demonstrating the soft power of China in the new era. It is a representative of the Chinese image in the non-traditional political and economic fields. As the "First Lady", his behavior and diplomatic posture have received more attention. China will further explore the connotation and actively exert his diplomatic role. Since the beginning of Chinese former President Jiang Zemin, China has intensified wife's diplomacy.

Afterwards, President Hu Jintao, President Xi Jinping with their wife, Prime minister Li Keqiang with wife appeared on the international diplomatic stage several times and received a warm welcome, creating a new situation in China's foreign affairs work. "First Lady" Peng Liyuan, as an ambassador for the prevention and treatment of AIDS, visited African AIDS families several times during her visit to African countries. When visited Europe, she introduced Chinese paper-cutting culture and national musical instruments to local women and children, highly recognized and praised by the international community. All this fully demonstrates the great potential of Madam's diplomacy. China is further deepening it's the styles, enhance international influence, and serve China's national image building.

6) Design and produce a national image propaganda film with a clear audience and target to enhance national influence

The national image propaganda film is a popular and effective national image construction tool in the world. At present, there are political, economic, cultural and comprehensive propaganda films, the main purpose of which is to express the country's good development aspirations and demonstrate the country's comprehensive soft power in science, technology, culture, economy, history, etc. Japan and South Korea have taken the lead in the production and launch of economic national promotional films. They have received huge public recognition from the international community and extended the social impression of Japanese and Korean manufacturing. The United States and the European Union have rich experience in the production of political national image propaganda films, and they use traditional methods to display Western-style values nurtured in propaganda films through multiple channels such as live broadcasts, interviewers, and so on. The influence should not be underestimated.

Since the beginning of the new century, China has gradually realized the great value of the national image propaganda film, and has begun to try to produce a series of films, in an attempt to change China's inherent stereotypes in the international community. In early 2011, China's national image film was broadcast in Times Square, New York, USA. In 60 seconds, the smiling faces and development achievements of the people from 31 provinces, cities and autonomous regions in China not only shocked the American people and the international community, but also actively sought change. The future of a better Chinese image has been successfully revealed to the world.

In 2018, the national publicity film "China enters a new era" once again appeared in Times Square in New York. This time, it showed China's confidence to the world in a newer, more open and aggressive attitude. A few days later, major enterprises of Chinese national brands, such as Wuliangye, Haier, and Huawei, competed to launch image videos on the big screen of Times Square in New York to further expand the world's reputation for "Made in China". It has also allowed the Chinese image of reform, innovation and progress to be continuously strengthened, and the publicity effect has become prominent.

\section{Conclusion}

In the 70 years since the founding of the People's Republic of China, China's national image has undergone many adjustments and its goals have gradually become clear. As a new strategic resource for promoting high-quality development of the country in the new era, the image of the country has an irreplaceable practical 
role and historical significance. China understands that changing the way the world views China is not a one-day process. More time, technology, paths and wisdom are needed, and Chinese need to become proactive, bring together multiple forces, integrate multiple channels and technology platforms, and substantially enhance the strategic role of the country's image. However, it remains to be seen how the strategy will work in the future.

\section{Acknowledgments}

This article is granted by The Chinese National Planning Office of Philosophy and Social Science(NSSFC) 2018 pedagogy project "Research for Citizen in Great Countries and Value Recognition in New Era", NO: BEA180114.

\section{References}

Liuji. (2019). 21st century national image under the overseas dissemination of Chinese culture. Journal of Shenyang University, $1,131$.

Matthew, S. H. (1993). THE Self-Perpetuating National Self-Image: Cognitive Biases in Perceptions of International Interventions. Political Psychology, 14, 1. https://doi.org/10.2307/3791394

Xi, J. P. (2013.) Building a Strong Socialist Cultural Power and Improving China's Soft Power in Culture, Xinhuanet. Retrieved from http://www.xinhuanet.com/politics/2013-12/31/c_118788013.htm

$\mathrm{Xi}$, J. P. (2017). The victory of building a moderately prosperous society in an all-round way to win the great victory of socialism with Chinese characteristics in the new era-Report at the 19th National Congress of the Communist Party of China.

Yu, H., \& Wang, H. (2014). National image concept analysis. China State Journal, 1, 16.

Zhang, K. (2018). Ideal and Reality: The Changes of China's National Image in the Past 40 Years. Academic Frontier, 6, 84.

\section{Copyrights}

Copyright for this article is retained by the author(s), with first publication rights granted to the journal.

This is an open-access article distributed under the terms and conditions of the Creative Commons Attribution license (http://creativecommons.org/licenses/by/4.0/). 